\title{
Scale-Dependent Feedback and Regular Spatial Patterns in Young Mussel Beds
}

\author{
Johan van de Koppel, ${ }^{1, *}$ Max Rietkerk, ${ }^{2, \dagger}$ Norbert Dankers, ${ }^{3, \star}$ and Peter M. J. Herman ${ }^{1, \varsigma}$
}

1. Centre for Estuarine and Marine Ecology, Netherlands Institute of Ecology (NIOO-KNAW), P.O. Box 140, 4400 AC Yerseke, The Netherlands;

2. Department of Environmental Sciences, Copernicus Institute, Utrecht University, P.O. Box 80115, 3508 TC Utrecht, The Netherlands;

3. Alterra, P.O. Box 167, 1790 AD Den Burg, The Netherlands

Submitted February 23, 2004; Accepted December 14, 2004;

Electronically published January 20, 2005

\begin{abstract}
In the past decade, theoretical ecologists have emphasized that local interactions between predators and prey may invoke emergent spatial patterning at larger spatial scales. However, empirical evidence for the occurrence of emergent spatial patterning is scarce, which questions the relevance of the proposed mechanisms to ecological theory. We report on regular spatial patterns in young mussel beds on soft sediments in the Wadden Sea. We propose that scale-dependent feedback, resulting from short-range facilitation by mutual protection from waves and currents and long-range competition for algae, induces spatial self-organization, thereby providing a possible explanation for the observed patterning. The emergent self-organization affects the functioning of mussel bed ecosystems by enhancing productivity and resilience against disturbance. Moreover, self-organization allows mussels to persist at algal concentrations that would not permit survival of mussels in a homogeneous bed. Our results emphasize the importance of self-organization in affecting the emergent properties of natural systems at larger spatial scales.
\end{abstract}

Keywords: regular patterns, spatially explicit models, self-organization, emergence.

In recent years, a large number of theoretical studies have pointed to the possibility of self-organized spatial pat-

\footnotetext{
* Corresponding author; e-mail: j.vandekoppel@nioo.knaw.nl.

† E-mail: m.rietkerk@geog.uu.nl.

¥ E-mail: norbert.dankers@wur.nl.

`E-mail: p.herman@nioo.knaw.nl.
}

Am. Nat. 2005. Vol. 165, pp. E66-E77. (c) 2005 by The University of Chicago. 0003-0147/2005/16503-40315\$15.00. All rights reserved. terning in predator-prey systems (Hassell et al. 1991; de Roos et al. 1998; Gurney et al. 1998). In spatially explicit models, predator-prey interactions may create large-scale coherent spatial structures that are either dynamic (e.g., spiral waves) or stable (e.g., stationary lattice or patchy patterns), starting from random initial conditions. Spatial patterns may have important consequences by facilitating persistence of otherwise unstable predator-prey interactions, stimulating coexistence of competing species, and increasing stability on large spatial scales (Hassell et al. 1994; Rohani et al. 1997; de Roos et al. 1998; Gurney et al. 1998; Gurney and Veitch 2000).

An important mechanism underlying patterning in most of the published predator-prey models is a strong interaction between predator and prey. Strong predation leads to local depletion of the prey, invoking heterogeneity in the prey population. Depending on the relative dispersal rates of prey and predator, this leads to stable occurrence of prey patches (de Roos et al. 1998) or to local collapse of the predator, which produces unstable wavelike spatial patterns in which the prey and predator are locked in an endless pursuit (Hassell et al. 1991; Gurney et al. 1998). Stable prey patches were predicted to occur if prey dispersal is much smaller than predator dispersal. Wave patterns traveling in space dominated the predator-prey interaction if dispersal rates were about equal (Hassell et al. 1991, 1994).

Despite an abundance of theoretical articles, empirical evidence for the occurrence of self-organized spatial patterns in predator-prey systems is scarce (Rohani et al. 1997). Noteworthy exceptions are empirical studies on the formation of patchy patterns in the Western tussock moth (Maron and Harrison 1997) and on traveling waves in the Canadian lynx (Ranta et al. 1997), vole (Ranta and Kaitala 1997; Kaitala and Ranta 1998), and larch bud moth (Bjornstad et al. 2002). Spatial patterning such as traveling waves has therefore been dismissed as little more than a peculiarity of theoretical models (Rohani et al. 1997). Hitherto, the lack of empirical support has limited recognition of self-organized spatial patterns as an important determi- 
nant of predator-prey interactions and ecosystem functioning.

In this article, we report on regular patterning, consisting of banding patterns perpendicular to the flow of the water, in beds of young blue mussels (Mytilus edulis). Spectral analysis confirms visual observations that mussel beds exhibit regularly spaced, bandlike patterns. Then we present a theoretical analysis of a mussel-algae system, suggesting that scale-dependent interaction of positive and negative feedback, involving coarse-scale competition for algae and fine-scale facilitation between mussels, induces spatial self-organization, which provides a potential explanation for the observed patterns. The model analysis shows that selforganized spatial heterogeneity improves productivity, resistance, and resilience of mussel beds. Our study adds to a growing body of studies from a wide range of systems emphasizing the importance of self-organization for ecosystem functioning (Levin 1992; Wootton 2001; Guichard et al. 2003).

\section{Patterning in Young Mussel Beds}

Mussels typically appear on soft sediment in dense aggregations, occurring at various spatial scales (Snover and Commito 1998; Kostylev and Erlandsson 2001). Mussels settle in dense beds that range in size from tens of meters to square kilometers. Within these beds, mussels form aggregations, in which dense patches alternate with sediment containing hardly any mussels. Within high-density patches, mussels in turn form clumps, in which they are interconnected via byssal threads. The adaptive value of aggregation mainly relates to reduction of wave disturbance and predatory losses (Bertness and Grosholz 1985; Okamura 1986; Cote and Jelnikar 1999; Hunt and Scheibling 2001, 2002). Aggregation, however, also imposes disadvantages because depletion of pelagic food in larger patches can severely reduce mussel growth (Newell 1990; Svane and Ompi 1993) and even lead to strongly distorted shell growth (Bertness and Grosholz 1985). These findings suggest that the spatial structuring of mussel beds may affect the growth of individual mussels.

Aerial surveys of beds of blue mussels in the Wadden Sea following strong mussel recruitment events in 1994 and 2001 revealed that aggregation in many young mussel beds resulted in the formation of regular patterns (e.g., fig. 1). Patterns were observed in young mussel beds in October, which implies that they developed in just a few months after the settling of larvae in May/June. Patterned beds are a temporary phenomenon because most young mussel beds in the Wadden Sea are either severely damaged or entirely removed by winter storms or fisheries. Those beds that survive the winter are heavily marked by wave disturbance, which is likely to destroy any regular pat- terning that has emerged during the prior growing season. Regular patterns range from sharply defined banded patterns to more diffuse patchy fragments (fig. 2, first row, $A$ and $B$ vs. $C$ ). Most banded patterns appeared to be aligned perpendicular to the flow of the water and appeared not to be associated with underlying structures in the sediment.

\section{Regularity in Mussel Band Patterns}

The formation of complex irregular patterns in mussel beds on rocky substrates has been described frequently (Paine and Levin 1981; Wootton 2001). Studies on pattern formation on sedimentary substrates are less abundant (but see Snover and Commito 1998), and regular patterning has not been reported from mussel beds on either soft or hard substrates. We studied patterned mussel beds in the Wadden Sea using digitized photographs to establish that the observed patterns were periodic and to provide a rough estimate of their spatial wavelength and orientation. Pictures were taken during an aerial survey on October 12 , 2001, at an altitude of about $900 \mathrm{~m}$ above sea level, each picture covering an area of about $480 \mathrm{~m} \times 620 \mathrm{~m}$. Visual inspection indicated that about $25 \%$ showed clear regular patterning, about $50 \%$ revealed some degree of regularity, and $80 \%$ of the photographs containing mussel beds were clearly patchy. We analyzed a small subset of the obtained images because our analysis aims just to show that regular patterning is a possible aspect of soft-sediment mussel beds. A thorough analysis of mussel bed patterns observed in the Wadden Sea is beyond the scope of this article. We tested for regularity in the observed patterns by applying two-dimensional spectral analysis (Renshaw and Ford 1983; Couteron and Lejeune 2001). Two $128 \times 128$-pixel and one $256 \times 256$-pixel subsections were selected from the images, covering a surface of about $25 \times 25 \mathrm{~m}$ and $50 \times 50 \mathrm{~m}$, respectively. The first two of the subsections were taken from images with (visually) clear regular bands (fig. $2 A, 2 B$ ). The last one was obtained from an image where patterning appeared less regular (fig. $2 C$ ). The subsections were taken from beds in the Wadden Sea located at 1.7, 1.0, and $2.8 \mathrm{~km}$ from the coastline, respectively. All subsections covered at least four wavelengths, confirmed by later analysis, which conforms to similar spectral analyses in the literature (Renshaw and Ford 1984; Couteron and Lejeune 2001). Moreover, enlarging of the subsections gave qualitatively similar results. All images were rescaled to $128 \times 128$ pixels and converted to gray-scale values (0-255). Dark pixels correspond to areas dominated by a dense mussel cover, whereas bright areas correspond to bare sediment.

In principle, spectral analysis provides a measure of the image variance explained by a simple cosine repeating itself 


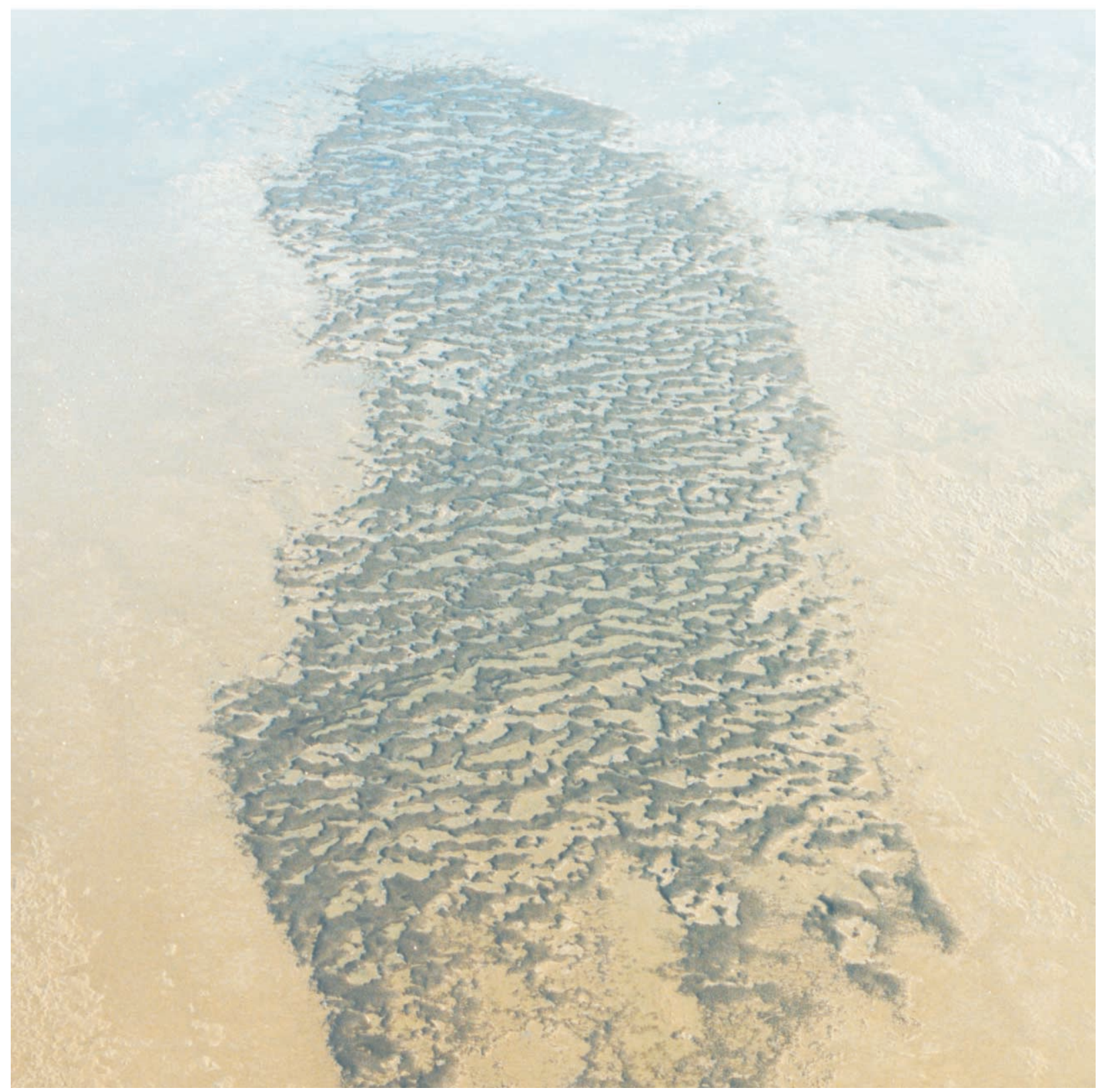

Figure 1: Aerial photograph of a patterned mussel bank in the Wadden Sea, The Netherlands. The scale is about $400 \times 600 \mathrm{~m}$. The photograph was taken in November 1994.

$r$ times along a travel direction $\theta$ (Couteron and Lejeune 2001), referred to as $I$. A plot of $I$ in a two-dimensional space is called a periodogram. In this periodogram, the distance from the center (marked by a star) and the angle relative to the vertical upward direction reflects the wave number $r$ and the angle $\theta$ (fig. 2, second row). To further investigate the periodogram, radial and angular spectra of $I$ are generated (fig. 2, third and fourth rows). The radial spectrum depicts the dominant wave number, irrespective of direction. The angular spectrum reveals the direction of the dominant cosine wave, ranging from $0^{\circ}$ to $180^{\circ}$ (note that angles beyond $180^{\circ}$ are redundant). Detailed treatments of the method can be found in articles by Renshaw and Ford (1984), Mugglestone and Renshaw (1998), and Couteron and Lejeune (2001).

The spectral analysis revealed clear regularity and di- 


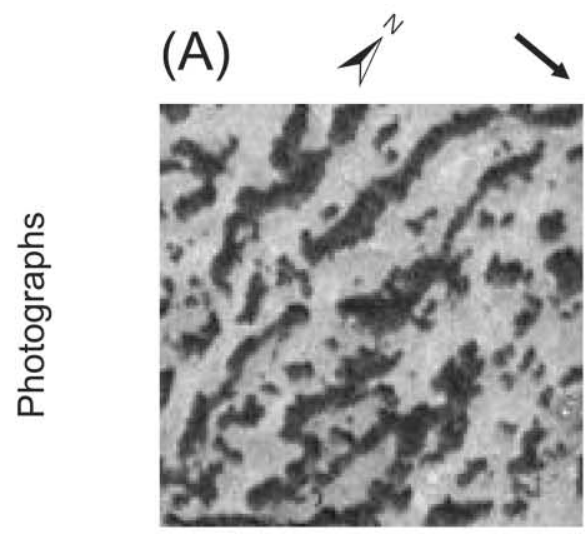

$25 \mathrm{~m}$ by $25 \mathrm{~m}$
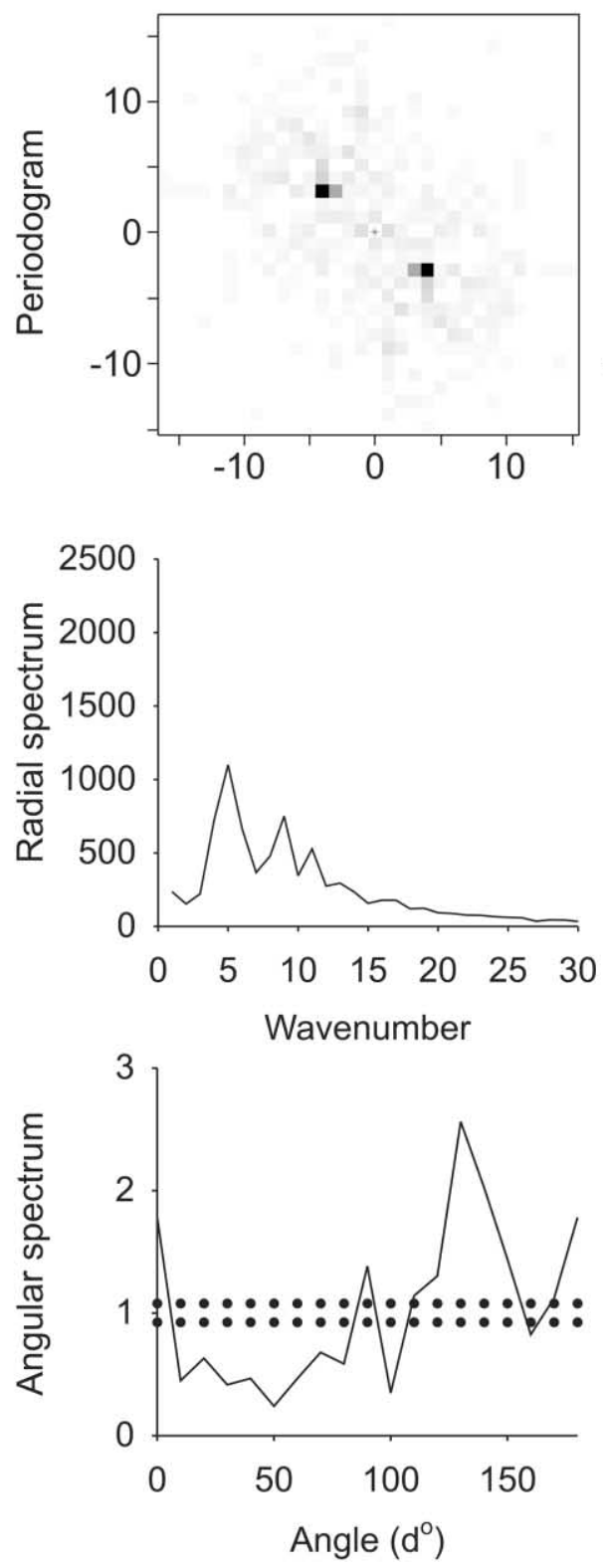

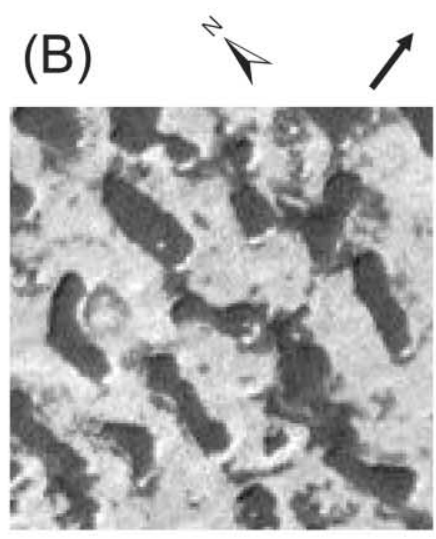

$25 \mathrm{~m}$ by $25 \mathrm{~m}$
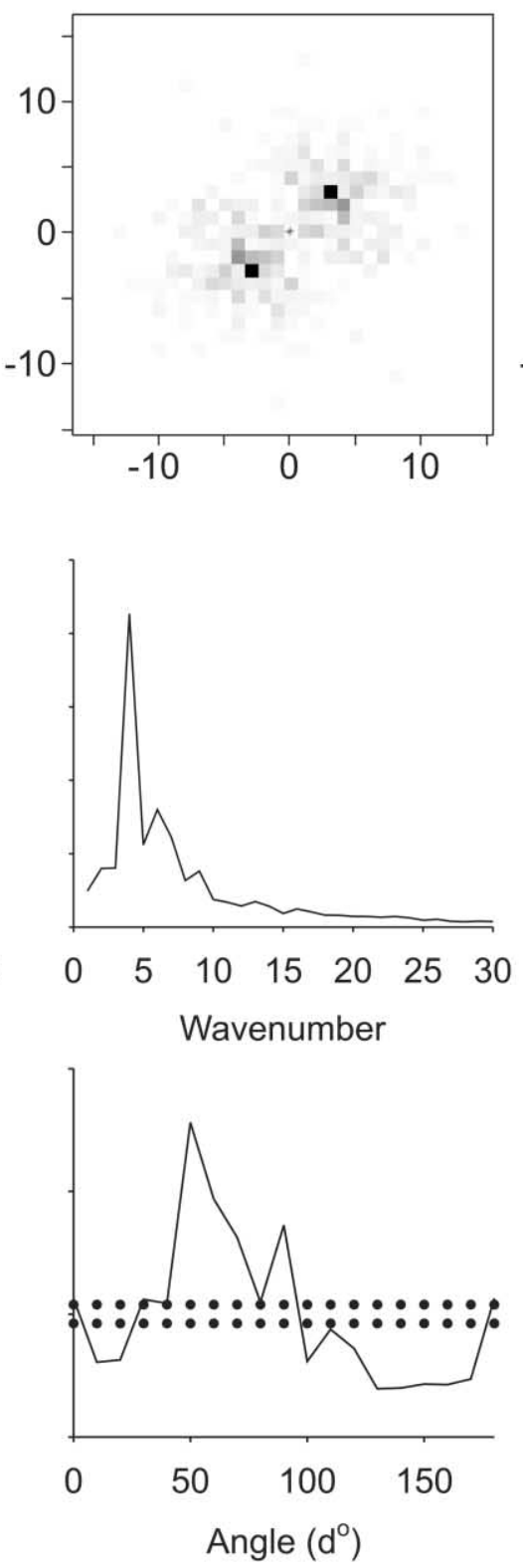

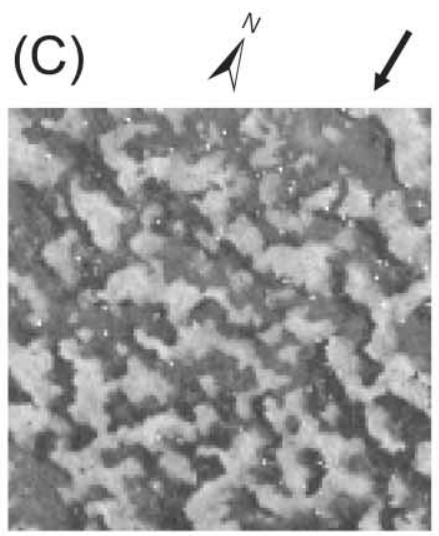

$50 \mathrm{~m}$ by $50 \mathrm{~m}$
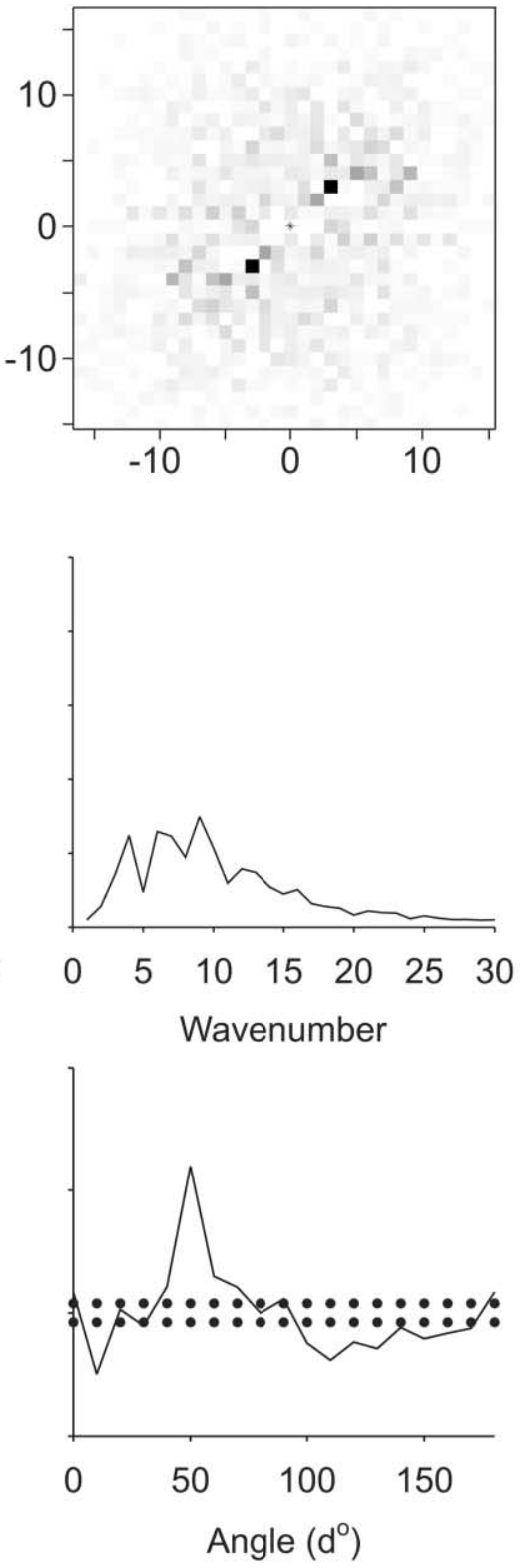
rectionality in the first two photographs (fig. $2 A, 2 B$ ). The dominant wave number was found to be $4-5$, which corresponds to a wavelength of about $6 \mathrm{~m}$. The smaller peaks at higher wave numbers are likely to be resonance. The bands were oriented to a dominant direction of $130^{\circ}$ and $50^{\circ}-60^{\circ}$ relative to the top edge of the picture. The orientation of the bands corresponded roughly with the direction of the flood current (fig. 2; van der Wal 2002). The patterning was less regular in the third photograph, and a dominant wave number was not clearly distinguished. A possible cause of lack of regularity is higher wave exposure. Despite its more patchy nature, the angular spectrum revealed a dominant direction of about $50^{\circ}$, pointing at a directional nature for potential explanatory mechanisms.

\section{A Simple Spatial Model}

Mussel growth and survival in soft-sediment mussel beds are strongly dependent on the availability of algal food sources and on loss rates due to dislodgment and predation. A significant body of literature exists that shows that, in soft-sediment or subtidal mussel beds, algal food availability limits intake by mussels (Wildish and Kristmanson 1984; Dolmer 2000; Widdows et al. 2002) and mussel growth (Frechette and Bourget 1985; Page and Hubbard 1987; Newell 1990; Muschenheim and Newell 1992; Frechette and Despland 1999; Oie et al. 2002). Dislodgment and predation depend strongly on local mussel density (Bertness and Grosholz 1985; Okamura 1986; Cote and Jelnikar 1999; Hunt and Scheibling 2001, 2002) because nearby conspecifics are the main substrate for attachment on soft-bottom sediment. The effects of competition are spread out over much larger distances because water depleted in algal stocks by mussels is carried over the mussel bed by the tidal currents. We hypothesize that the scale-dependent interaction between short-range facilitation and long-range competition for algae explains the observed patterning in mussel banks. Here, we provide support for this hypothesis by means of a simple spatially explicit model describing changes in local population biomass of algae and mussels.

Predation of algae by mussels on soft sediment occurs mostly in the lower water layer (Wildish and Kristmanson 1984; Muschenheim and Newell 1992). Predation is matched by influx of algae from upper water layers and by lateral transport of algae through tidal currents and, to a lesser extent, turbulent diffusion. We furthermore assume that the upper water layer is not affected by the consumption of the mussels. Changes in the concentration of algae $A$ in the water layer overlying a particular spot on the mussel bed can be described by

$$
\frac{\partial A}{\partial t}=\left(A_{\text {up }}-A\right) f-\frac{c}{h} A M-V \nabla_{y} A .
$$

Here $A_{\text {up }}$ describes the concentration of algae in the upper water layer, $f$ is the rate of exchange between the lower and upper water layers, $c$ is the consumption constant, $h$ is the height of the lower water layer, and $M$ is the mussel density. Advection by tidal current is represented by the gradient operator $\nabla A$ multiplied by the advection constant $V$. For this simple model, we assume a unidirectional flow of water because the flood flow is likely to be most important in supplying algal food to the mussel bed.

The rate of change of mussel biomass per square meter of sediment surface is described by

$$
\frac{\partial M}{\partial t}=e c A M-d_{\mathrm{M}} \frac{k_{\mathrm{M}}}{k_{\mathrm{M}}+M} M-D \Delta M .
$$

Here $e$ is the conversion constant of ingested algae to mussel production, $d_{\mathrm{M}}$ is the maximal per capita mussel mortality rate, and $D$ is the diffusion rate of the mussels. The model assumes a simple predator-prey interaction between algae and mussels with a linear functional response. The per capita mortality of the mussels is assumed to decrease with increasing mussel density because of a reduction of dislodgment and predation in dense clumps. This is represented by the term $k_{\mathrm{M}} /\left(k_{\mathrm{M}}+M\right)$, where $k_{\mathrm{M}}$ is the value of $M$ at which mortality is half maximal. We furthermore assume that movement of mussels is random and therefore adopt the classical diffusion approximation, where diffusion is a linear function of the Laplacian operator $\Delta M$ (Holmes et al. 1994). Table 1 provides an overview of the parameter values used, their units, and sources. We were able to obtain parameter values from the literature for all parameters except for $f, k_{\mathrm{M}}, d_{\mathrm{M}}$, and $D$, which were given plausible values.

In the above model, we ignore many details of the es-

Figure 2: Spectral analysis of three digital photographs of mussel bed patterns. The first two pictures represent $25 \times 25$-m sections of clearly banded mussel banks, whereas the last photograph represents a $50 \times 50-\mathrm{m}$ pattern with less clear directionality. The arrows above the photographs represent northern direction and flood current direction (obtained from tidal current charts), respectively. The second row represents the periodograms of the above pictures, its center indicated by a star. The third and fourth rows represent the radial and angular spectra of the periodograms and indicate the dominant wave number (number of waves in the photographs) and dominant direction of the pattern. Note that the lower section of the periodogram is a rotated copy of the upper section. Angles above $180^{\circ}$ are therefore redundant. 
Table 1: Parameter values used in the simulation

\begin{tabular}{|c|c|c|c|}
\hline Symbol & Value & Unit & Source $^{a}$ \\
\hline$A_{\text {up }}$ & 1 & $\mathrm{~g} / \mathrm{m}^{3}$ & $\begin{array}{l}\text { Cadee and Hegeman } \\
2002\end{array}$ \\
\hline$h$ & .1 & $\mathrm{~m}$ & $\begin{array}{l}\text { Wildish and Krist- } \\
\text { manson 1984; } \\
\text { Muschenheim and } \\
\text { Newell } 1992\end{array}$ \\
\hline$f$ & 100 & $\mathrm{~m}^{3} / \mathrm{m}^{3} / \mathrm{h}$ & Estimated \\
\hline$c$ & .1 & $\mathrm{~m}^{3} / \mathrm{g} / \mathrm{h}$ & $\begin{array}{l}\text { Scholten and Smaal } \\
\text { 1998; Riisgard } \\
2001\end{array}$ \\
\hline$e$ & .2 & $\mathrm{~g} / \mathrm{g}$ & Sukhotin et al. 2002 \\
\hline$d_{\mathrm{M}}$ & .02 & $\mathrm{~g} / \mathrm{g} / \mathrm{h}$ & Estimated \\
\hline$k_{\mathrm{M}}$ & 150 & $\mathrm{~g} / \mathrm{m}^{2}$ & Estimated \\
\hline$V$ & $360(10)$ & $\mathrm{m} / \mathrm{h}(\mathrm{cm} / \mathrm{s})$ & Brinkman et al. 2002 \\
\hline$D$ & .0005 & $\mathrm{~m}^{2} / \mathrm{h}$ & Estimated \\
\hline
\end{tabular}

Note: Parameter values were based on empirical studies in literature. No data were available for $f, d_{\mathrm{M}}, k_{\mathrm{M}}$, and $D$, which were estimated. Note that mussels in young mussel beds have low individual weight, which explains the high weight-specific filtration rate.

${ }^{a}$ Values obtained or derived.

tablishment of juvenile mussels on the sediment, such as the physiological changes in young mussels that occur during early development. Nevertheless, the model allows us to investigate the consequences of the scale-dependent feedback that is imposed by short-range facilitation and long-range competition on the development of a mussel bed. We investigated the development of mussels using two-dimensional numerical simulation with forward Euler integration of the finite difference equations. We used a rectangular spatial grid consisting of $100 \times 100$ cells, with a unidirectional water flow in the $y$ direction. We assume the simulated domain to be a section of a larger mussel bed. For this reason, we adopted periodic boundary conditions in the flow direction $(y)$ to mimic predepletion of the water by the bed surrounding the simulated domain. Reflecting boundaries were adopted in the other $(x)$ direction. Starting conditions consisted of a homogeneous equilibrium that was randomly perturbed.

The numerical solution revealed that for low values of $A_{\text {up }}$, the homogeneous equilibrium was unstable against small spatially heterogeneous perturbations. Under these conditions, even the smallest amount of spatial heterogeneity leads to the development of regular patterns of dense mussel bands consisting of dense mussel bands alternating with almost bare sediment and low mussel densities (fig. 3). In the mussel bands, algal concentrations in the lower water layer are quickly depleted, whereas in between the bands, concentrations are replenished by the mixing of the lower and upper layers. The bands slowly move upstream as mussels are able to establish in front of the bands. This leads to starvation of mussels on the downstream side of the bands. If simulations are allowed for an extended time, the model evolves toward a solution of straight parallel bands. During transient dynamics, banding is irregular, closely resembling the patterns observed in the field (fig. 3).

The occurrence of self-organized patterning is strongly affected by both biotic or abiotic conditions such as the availability of algae in the overlying water. For this reason, we investigated the sensitivity of the model to changes in parameter values. To focus on the parameters essential to the model behavior, we derived a nondimensional version of the above model based on equations 1 and 2 :

$$
\begin{aligned}
& \frac{\partial \alpha}{\partial \tau}=\gamma(1-\alpha)-\alpha \mu-\nu \nabla \alpha, \\
& \frac{\partial \mu}{\partial \tau}=\eta \alpha \mu-\delta \frac{\mu}{1+\mu}+\Delta \mu .
\end{aligned}
$$

Here $\alpha=A_{\text {up }}^{-1} A, \mu=k_{\mathrm{M}}^{-1} M, \gamma=f T^{-1}, \nu=V D^{-1 / 2} T^{-1 / 2}$, $\delta=d_{\mathrm{M}} T^{-1}, \eta=e c A_{\text {up }} T^{-1}$, and spatial dimension is rescaled to $T^{1 / 2} D^{-1 / 2} x$, where $T=c k_{\mathrm{M}} h^{-1}$ is the characteristic rate of filtration by the mussels to which time $t$ is rescaled $(\tau=T t)$. Hence, the nondimensional model has only four essential parameters that determine the dynamics of the model: renewal rate $\gamma$, water flow rate $\nu$, scaled potential growth rate $\eta$, and mussel maximal mortality $\delta$.

The analysis reveals the dependence of pattern formation on algal density in the overlying water $A_{\text {up}}$, which is reflected in model 3 by $\eta$. We first analyzed behavior of the homogenous solution of system 3 , in which the gradient and Laplacian operators are set to 0 . A homogenous equilibrium is found at $\eta>\delta$, which increases strongly with algal input $\eta$ (fig. 4, blue line). Numerical analysis, however, indicates that the homogenous equilibrium is unstable to small spatially heterogeneous perturbations when $\eta<0.188$. These perturbations lead to the formation of regular banded patterns (fig. 4, dashed red line). This phenomenon is similar to a Turing bifurcation, but it differs in that it results in part from differential movement due to advection instead of diffusion (cf. Rovinsky and Menzinger 1992, 1993; Rovinsky et al. 1997). At high values of $A_{\text {up }}$ (or $\eta$ ), no pattern formation occurs, because the homogeneous equilibrium is resistant to small spatially heterogeneous perturbations. Note that as a result of the simplistic mortality function that was used, the model produces unrealistically high equilibrium mussel densities at $\eta>0.20$.

The model points to a number of ecologically important consequences of the formation of regular patterns. First, the total amount of mussels, averaged over the entire simulated domain, is increased by the formation of regular patterns relative to the density predicted by the homo- 

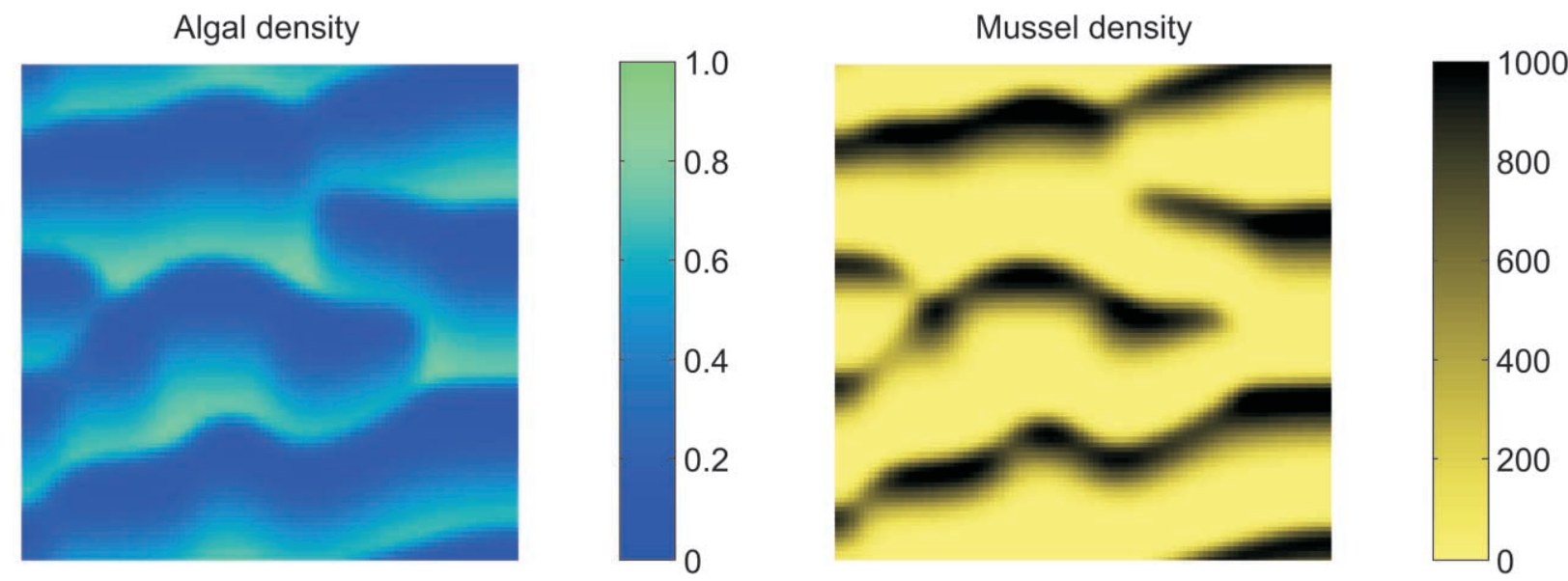

Figure 3: Simulated spatial patterns in algal concentration $(\mathrm{mg} / \mathrm{L})$ and mussel density on the sediment $\left(\mathrm{g} / \mathrm{m}^{2}\right)$. The scale is about $25 \times 25 \mathrm{~m}$. Original parameters as in table 1. Rescaled parameter values used: $\gamma=0.667, \nu=1,315, \eta=1.33 \times 10^{-4}, \delta=1.33 \times 10^{-4}$.

geneous model (fig. 4, dashed blue line vs. dashed-anddotted green line). Consequently, the observed patterns are predicted to increase the productivity of the mussel bed. Second, the range at which banded patterns occurs extends into a region where mussels are unable to persist if they would have been homogeneously spread out because food availability would be too low to support mussel growth (e.g., $\eta<0.133$ ). This has two important implications. Pattern formation increases the resistance of mussel beds to low algal concentrations. Moreover, below $\eta=0.133$, the system has two stable states, one characterized by regular patterns, whereas in the other state mussels cannot survive. Hence, mussel beds at very low algal input rates are predicted to be sensitive to disturbances and might be unable to recover if human intervention or storms remove large numbers of mussels.

We investigated the consequences of pattern formation on the resilience of mussel bed systems to disturbances. We imposed a disturbance on a banded mussel bed at equilibrium biomass, in which the density of the mussels was reduced to $60 \%$. We compared the recovery time to equilibrium in three simulation runs. In the first simulation, we reduced the density but left the spatial patterning intact. In the second simulation, we reduced the density, evenly redistributed the remaining mussels over the simulated grid, and then imposed a random deviation on each simulated cell of maximally $10 \%$ of the within-cell biomass. In the last simulation, we reduced the density and completely homogenized the bed, leaving no spatial variability (e.g., all simulated cells had the same biomass). We found that the simulation in which the patterns were left intact quickly recovered to their former equilibrium biomass (fig. 5, dashed line). The simulation in which the mussels were randomly redistributed showed a significant lag in its recovery (fig. 5, dotted line). At first, little recovery occurred as the mussels reorganized into bands. After reemergence of the patterns, mussel density quickly recovered to the equilibrium values that existed before the disturbance. In the last simulation, all heterogeneity was removed, and hence no patterns developed (small deviations from homogeneity are required to initiate pattern formation). Mussel density remained low, as little recovery occurred (fig. 5, solid line). Hence, the simulation demonstrates that self-organized spatial patterns strongly improve the resilience of mussel bed systems to disturbances that reduce mussel density relative to unpatterned beds.

Although our model is well able to explain pattern formation, it is still a large simplification of the complexity of mussel-algae interaction. First, we used a linear functional and numerical response to describe the interactions between mussels and algae. Although intake continues to be high at high algal concentrations, mussels become more selective, which results in the dumping of low-quality algal material as pseudofeces. This leads to saturation of growth. Inclusion of saturation affects model predictions quantitatively, but our conclusions remained qualitatively the same. Second, mussels actively move into the water currents, maximizing their exposure to algae-rich water. We analyzed a model in which the mussels actively moved toward a high concentration of algae. Similar patterns emerged in this model, albeit on a shorter timescale. The model presented in this article therefore underestimates the rate at which patterns could develop in nature. We chose to ignore these aspects of mussel ecology, however, because we wanted to focus on the essential mechanisms that could potentially explain pattern formation. 


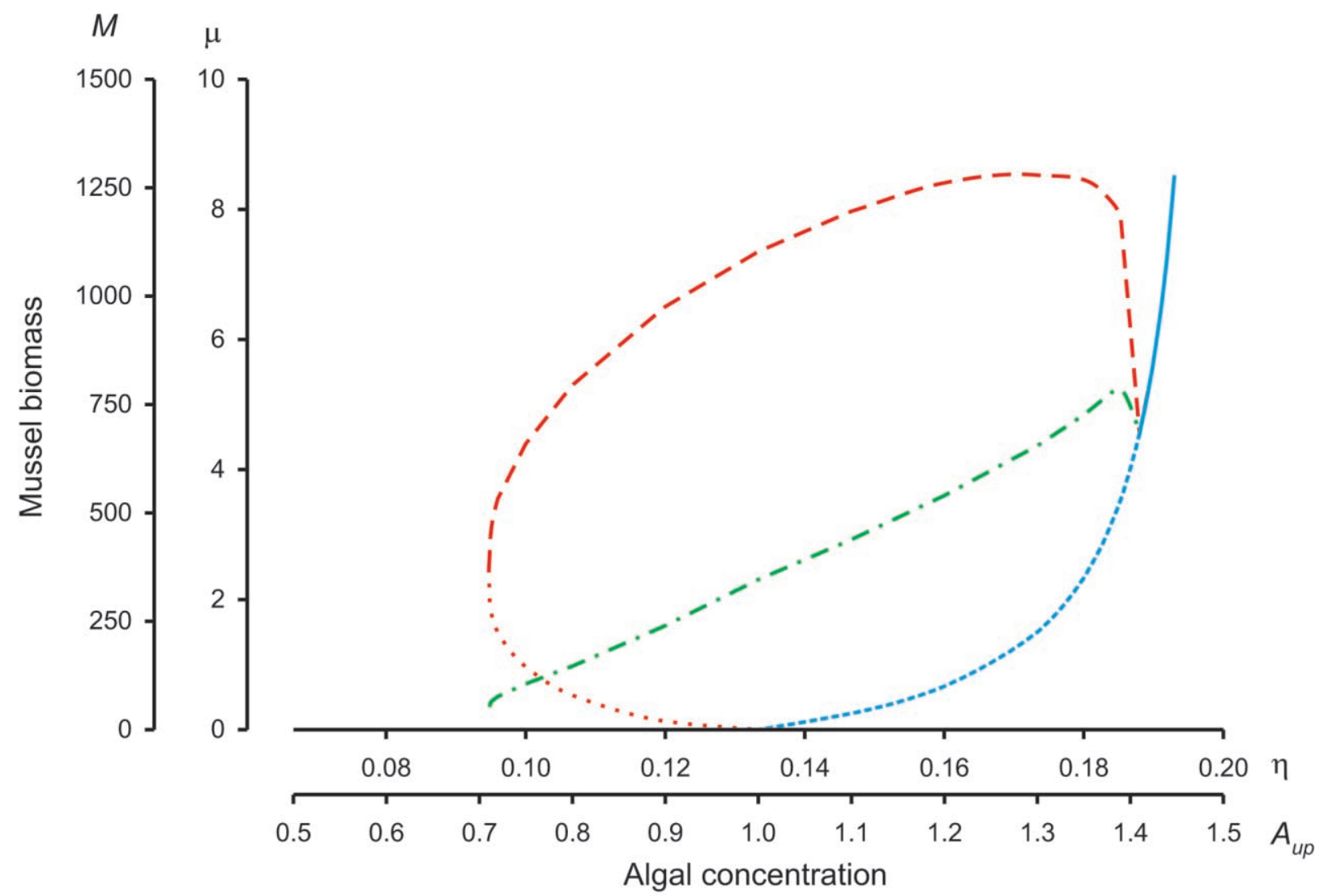

Figure 4: Bifurcation analysis of the one-dimensional single peak solution of system 3 along a spatial range of $10 \mathrm{~m}$. The solid blue line represents the stable homogeneous equilibrium, whereas the dashed blue line represents the homogeneous equilibrium where it is unstable to spatially heterogeneous perturbations. The dashed red line represents the maximal biomass in the nonhomogeneous (patterned) equilibria, and the dashedand-dotted green line represents the average biomass in the nonhomogeneous equilibrium. The dotted red line represents the unstable nonhomogenous equilibrium below which the mussel beds collapse (e.g., a threshold). The homogeneous solution was obtained analytically, whereas the heterogeneous solutions were obtained using iterative simulations. Parameters as in table 1, apart from $A_{\mathrm{up}} / \eta$.

\section{Discussion}

In this article, we report on clearly visible, regular spatial patterning in a predator-prey system. Aerial photographs of young mussel beds on soft-bottom sediment revealed banded patterns, which were confirmed to be regular by spectral analysis. We demonstrate by means of a simple mathematical model that the patterns can potentially be explained by the interaction of a small-scale positive and large-scale negative feedback to the growth of juvenile mussels. The positive feedback involves small-scale aggregation of mussels due to the formation of byssal threads, which protects mussels from erosion by waves and water currents as their densities increase. Negative feedback results from depletion of algal food sources from the lower water layers and acts at much larger distances. Selforganization, resulting from the interaction between these feedbacks, combined with a unidirectional flow of food sources, potentially explains the formation of regular patterns in young mussel beds.

Our explanation centers on a strong predator-prey interaction between mussels and their algal food source, leading to depletion of algal densities in the lower water layer, even in relatively narrow mussel bands. This hypothesis concurs with an extensive body of literature reporting that depletion of the algae in lower water layers limits the growth of mussels in real (Frechette and Bourget 1985; Newell 1990; Muschenheim and Newell 1992; Frechette and Despland 1999; Dolmer 2000) and artificial conditions (Wildish and Kristmanson 1984; Widdows et al. 2002). Moreover, mussels were found to generate local heterogeneity in the concentration of algae in the lower water layers, even on spatial scales of $<10 \mathrm{~m}$ (Asmus et al. 1992; L. A. van Duren and J. K. Petersen, personal communication). A number of studies emphasize the im- 


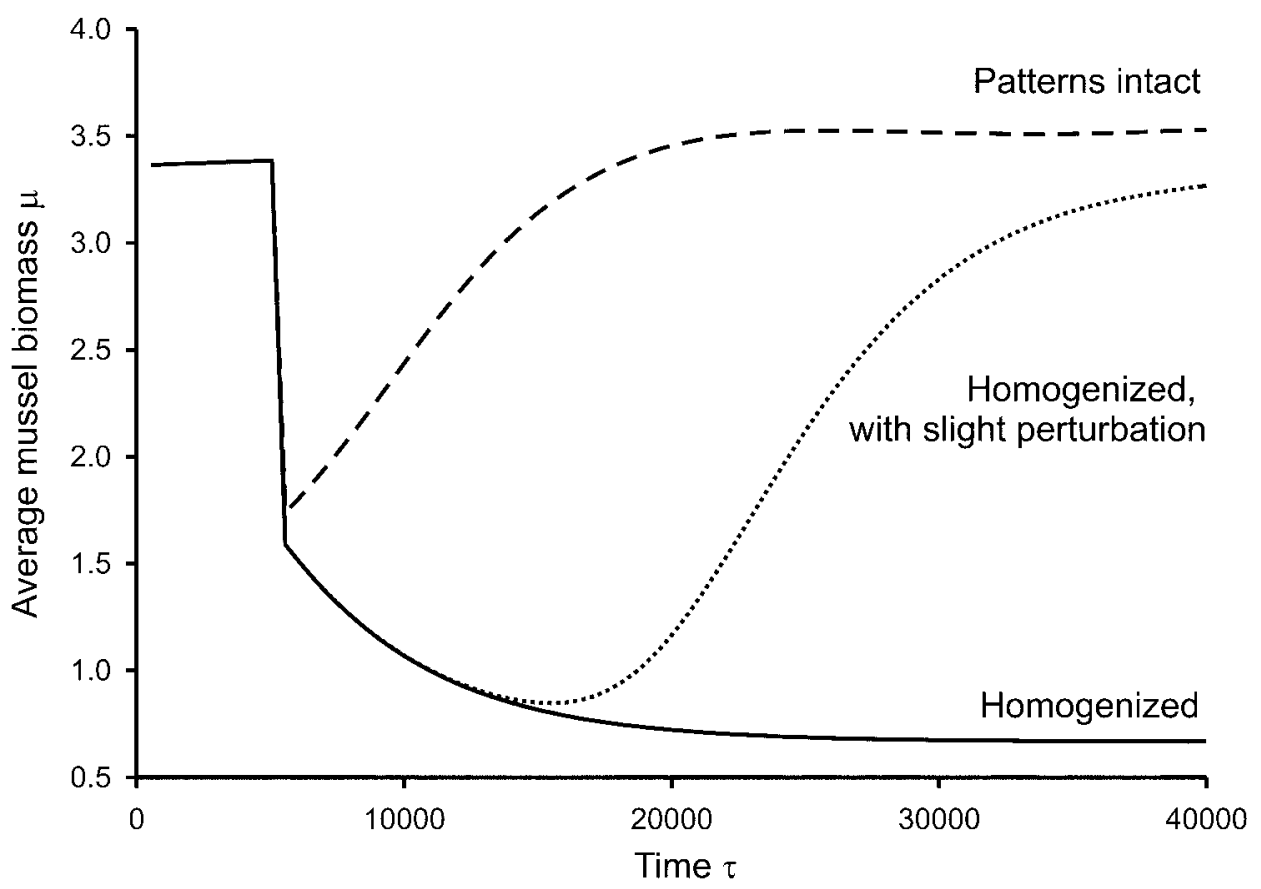

Figure 5: Results of three simulations using the nondimensional model, describing the recovery of a mussel bed after a perturbation in which the density of mussels was reduced by $60 \%$. The dashed line represents a simulation where the patterns were left intact. The dotted line represents a simulation where the mussels and algae were evenly redistributed, after which a random deviation was imposed on each cell of maximally $10 \%$ of the biomass. The solid line represents a simulation in which the mussels and algae were homogenized in space, leaving no spatial variability. Units are nondimensional. Parameters as in table 1, apart from $A_{\mathrm{up}}: 1.2 \mathrm{~g} / \mathrm{m}^{3}$.

portance of patch size and positions within a patch for mussel growth (Okamura 1986; Svane and Ompi 1993). Although adult mussels are relatively sedentary, juvenile mussels are able to show extensive movement (Toomey et al. 2002). Moreover, mussels are known to reorganize in relation to wave disturbance or small-scale differences in food availability (Hunt and Scheibling 2002), a property essential for self-organization to occur. As mussels mature, however, the ability of mussel beds to self-organize will diminish; little within-patch movement has been observed in mussels $>20 \mathrm{~mm}$ (Okamura 1986).

There are several potential alternative explanations for the heterogeneity of mussel distribution observed in the Wadden Sea. First, banded patterns could result from differentiated settling on sediment structures such as megaripples. However, the water current velocities that are required for the formation of megaripples with a wavelength of $8 \mathrm{~m}$ far exceed the conditions under which mussels could settle and survive on soft substrate (Amos and King 1984). Second, increased turbulence over mussel beds could create an incentive for mussel aggregation. Turbulence may affect the influx of algae from higher water layers and induce heterogeneity in the availability of algae. Although this may contribute to aggregation of mussels, it does not provide an explanation for the observed regularity in the patterns. Finally, wave action may cause banding in mussel beds. If this is true, then patterning should disappear with increased distance from the bed edge because the waves would be attenuated over the bed. This we did not observe (see fig. 1). Since these alternative explanations were unable to provide a strong alternative, we propose that the interaction of prey depletion and local facilitation is the most likely cause of the observed regular patterns.

Although it essentially describes a predator-prey system, our model clearly deviates from those used by most theoretical studies on spatial predator-prey dynamics (Hassell et al. 1991; de Roos et al. 1998; Gurney et al. 1998). Spatial patterning in most predator-prey systems results from the interaction of a saturating functional response and logistic prey growth, leading to spatiotemporal instability (i.e., population cycles and traveling waves). In our model of mussel beds, patterning is due to an altogether different mechanism: reduced mussel (i.e., the predator) mortality at high mussel density, leading to intraspecific facilitation, which stimulates aggregation of mussels. Overexploitation of the prey, as in the classical models, limits the size of mussel bands and generates the observed regularity. Our study conforms with studies from arid ecosystems that 
report on self-organized patterning in arid vegetation (Klausmeier 1999; Couteron and Lejeune 2001; von Hardenberg et al. 2001; Lejeune et al. 2002; Rietkerk et al. 2002). Both systems share a common principle explaining pattern formation: growth of organisms induces a local positive feedback (i.e., low loss in mussel beds), stimulating further growth on a small spatial scale. Growth of organisms also causes a negative feedback (i.e., depletion of algae or water) that decreases growth and acts at larger spatial scales. These scale-dependent feedback processes are similar to Turing's principle (Turing 1952), which explains pattern formation in a wide range of scientific disciplines, including structured rock distribution in polar environments (Kessler and Werner 2003) and pattern formation on sea shells (Meinhardt 1995).

Application of statistical mechanics to ecological systems has recently led to a wave of studies emphasizing the importance of self-organized criticality in determining the spatial complexity of ecosystems (Malamud et al. 1998; Clar et al. 1999; Pascual et al. 2001, 2002a, 2002b; Wootton 2001; Seuront and Spilmont 2002; Sole et al. 2002). In mussel beds on intertidal rocky shores, where mussels compete mostly for space (Bertness 1999), spatial patterning results from localized small-scale instabilities in the form of unstable mussel bed edges (Guichard et al. 2003). These local instabilities percolate through the system, generating self-organized scale-invariant patchiness. The patterns predicted by models with criticality are principally different from those predicted by the models presented in our study because regularity is absent in models with criticality (Bak 1996). Hence, the patterns observed in our system suggest that scale-dependent feedback rather than percolating disturbance is the underlying cause of the spatial complexity of our Wadden Sea mussel beds.

Our analysis points at important implications of spatial complexity generated by self-organization for the functioning of mussel bed ecosystems. Our model predicts that mussel beds with self-organized spatial patterns have higher productivity, in terms of realized biomass, and higher resilience than models without patterns. Moreover, the model predicts that self-organized patterning allows mussels to persist at algal concentrations that would not allow persistence in a homogeneous bed. A similar effect of spatial patterning was found in arid ecosystems, in that resilience, growth, and persistence of vegetation at low rainfall levels were strongly improved (Ludwig et al. 1999; von Hardenberg et al. 2001; Rietkerk et al. 2002; van de Koppel and Rietkerk 2004). Spatial redistribution of surface water between patches because of lateral flow improved the efficiency of water harvesting by the vegetation, increasing production and lowering water losses from the system (Ludwig and Tongway 1995; Ludwig et al. 1999; Valentin and d'Herbes 1999; Valentin et al. 1999). Hence, our study highlights that self-organization may influence the flow of resources through the ecosystem and thereby affects the functioning of ecosystems at larger spatial scales.

There is a growing body of studies pointing to the importance of self-organization in natural ecosystems (Klausmeier 1999; von Hardenberg et al. 2001; Wootton 2001; Rietkerk et al. 2002; Guichard et al. 2003). A common property seems to link these systems: regular patterns are mostly reported from systems where the abiotic environment is relatively homogenous at the scale at which patterning occurs (i.e., a flat habitat lacking environmental gradients). As a logical consequence, interactions between organisms and their environment are the dominant structuring force. In most ecosystems, however, the abiotic environment is far from homogenous because the landscape is complex and dominated by gradients in physical or chemical stress and resource availability. How important self-organization is in such ecosystems will be a central question for future research on complexity in ecological systems.

\section{Acknowledgments}

We thank M. Bertness, S. Dekker, A. de Roos, F. Guichard, P. Lundberg, K. Reise, L. van Duren, F. Weissing, and three anonymous reviewers for helpful suggestions and comments on earlier versions of the manuscript and W. Bouten for the program frame on which the simulations in this article were based. The research of M.R. is supported by the Netherlands Organization of Scientific Research/Earth and Life Sciences (NWO-ALW). This is publication 3467 of the Netherlands Institute of Ecology.

\section{Literature Cited}

Amos, C. L., and E. L. King. 1984. Sand waves and sand ridges of the Canadian Eastern Seaboard: a comparison to global occurrences. Marine Geology 57:167-208.

Asmus, H., R. M. Asmus, T. C. Prins, N. Dankers, G. Frances, B. Maass, and K. Reise. 1992. Benthic-Pelagic flux rates on mussel beds: tunnel and tidal flume methodology compared. Helgolander Meeresuntersuchungen 46:341-361.

Bak, P. 1996. How nature works. Springer, New York.

Bertness, M. D. 1999. The ecology of Atlantic shoreline. Sinauer, Sunderland, MA.

Bertness, M. D., and E. Grosholz. 1985. Population dynamics of the ribbed mussel, Geukensia demissa: the costs and benefits of a clumped distribution. Oecologia (Berlin) 67:192-204.

Bjornstad, O. N., M. Peltonen, A. M. Liebhold, and W. Baltensweiler. 2002. Waves of larch budmoth outbreaks in the European Alps. Science 298:1020-1023.

Brinkman, A. G., N. Dankers, and M. van Stralen. 2002. An analysis of mussel bed habitats in the Dutch Wadden Sea. Helgoland Marine Research 56:59-75.

Cadee, G. C., and J. Hegeman. 2002. Phytoplankton in the Marsdiep at the end of the 20th century: 30 years monitoring biomass, 
primary production, and Phaeocystis blooms. Journal of Sea Research 48:97-110.

Clar, S., B. Drossel, K. Schenk, and F. Schwab. 1999. Self-organized criticality in forest-fire models. Physica A Statistical Mechanics and Its Applications 266:153-159.

Cote, I. M., and E. Jelnikar. 1999. Predator-induced clumping behaviour in mussels (Mytilus edulis Linnaeus). Journal of Experimental Marine Biology and Ecology 235:201-211.

Couteron, P., and O. Lejeune. 2001. Periodic spotted patterns in semiarid vegetation explained by a propagation-inhibition model. Journal of Ecology 89:616-628.

de Roos, A. M., E. McCauley, and W. G. Wilson. 1998. Pattern formation and the spatial scale of interaction between predators and their prey. Theoretical Population Biology 53:108-130.

Dolmer, P. 2000. Algal concentration profiles above mussel beds. Journal of Sea Research 43:113-119.

Frechette, M., and E. Bourget. 1985. Food-limited growth of Mytilus edulis L. in relation to the benthic boundary layer. Canadian Journal of Fisheries and Aquatic Sciences 42:1166-1170.

Frechette, M., and E. Despland. 1999. Impaired shell gaping and food depletion as mechanisms of asymmetric competition in mussels. Ecoscience 6:1-11.

Guichard, F., P. M. Halpin, G. W. Allison, J. Lubchenco, and B. A. Menge. 2003. Mussel disturbance dynamics: signatures of oceanographic forcing from local interactions. American Naturalist 161: 889-904.

Gurney, W. S. C., and A. R. Veitch. 2000. Self-organization, scale and stability in a spatial predator-prey interaction. Bulletin of Mathematical Biology 62:61-86.

Gurney, W. S. C., A. R. Veitch, I. Cruickshank, and G. McGeachin. 1998. Circles and spirals: population persistence in a spatially explicit predator-prey model. Ecology 79:2516-2530.

Hassell, M. P., H. N. Comins, and R. M. May. 1991. Spatial structure and chaos in insect population-dynamics. Nature 353:255-258.

. 1994. Species coexistence and self-organizing spatial dynamics. Nature 370:290-292.

Holmes, E. E., M. A. Lewis, J. E. Banks, and R. R. Veit. 1994. Partial differential equations in ecology: spatial interactions and population dynamics. Ecology 75:17-29.

Hunt, H. L., and R. E. Scheibling. 2001. Patch dynamics of mussels on rocky shores: integrating process to understand pattern. Ecology 82:3213-3231.

- 2002. Movement and wave dislodgment of mussels on a wave-exposed rocky shore. Veliger 45:273-277.

Kaitala, V., and E. Ranta. 1998. Travelling wave dynamics and selforganization in a spatio-temporally structured population. Ecology Letters 1:186-192.

Kessler, M. A., and B. T. Werner. 2003. Self-organization of sorted patterned ground. Science 299:380-383.

Klausmeier, C. A. 1999. Regular and irregular patterns in semiarid vegetation. Science 284:1826-1828.

Kostylev, V., and J. Erlandsson. 2001. A fractal approach for detecting spatial hierarchy and structure on mussel beds. Marine Biology 139:497-506.

Lejeune, O., M. Tlidi, and P. Couteron. 2002. Localized vegetation patches: a self-organized response to resource scarcity. Physical Review E 66. Article 010901.

Levin, S. A. 1992. The problem of pattern and scale in ecology. Ecology 73:1943-1967.

Ludwig, J. A., and D. J. Tongway. 1995. Spatial organisation of land- scapes and its function in semi-arid woodlands, Australia. Landscape Ecology 10:51-63.

Ludwig, J. A., D. J. Tongway, and S. G. Marsden. 1999. Stripes, strands or stipples: modelling the influence of three landscape banding patterns on resource capture and productivity in semi-arid woodlands, Australia. Catena 37:257-273.

Malamud, B. D., G. Morein, and D. L. Turcotte. 1998. Forest fires: an example of self-organized critical behavior. Science 281:18401842.

Maron, J. L., and S. Harrison. 1997. Spatial pattern formation in an insect host-parasitoid system. Science 278:1619-1621.

Meinhardt, H. 1995. The algorithmic beauty of sea shells. Springer, Berlin and Heidelberg.

Mugglestone, M. A., and E. Renshaw. 1998. Detection of geological lineations on aerial photographs using two-dimensional spectral analysis. Computers and Geosciences 24:771-784.

Muschenheim, D. K., and C. R. Newell. 1992. Utilization of seston flux over a mussel bed. Marine Ecology Progress Series 85:131136.

Newell, C. R. 1990. The effects of mussel (Mytilus edulis, Linnaeus, 1758) position in seeded bottom patches on growth at subtidal lease sites in Maine. Journal of Shellfish Research 9:113-118.

Oie, G., K. I. Reitan, O. Vadstein, and H. Reinertsen. 2002. Effect of nutrient supply on growth of blue mussels (Mytilus edulis) in a landlocked bay. Hydrobiologia 484:99-109.

Okamura, B. 1986. Group living and the effects of spatial position in aggregations of Mytilus edulis. Oecologia (Berlin) 69:341-347.

Page, H. M., and D. M. Hubbard. 1987. Temporal and spatial patterns of growth in mussels Mytilus edulis on a offshore platform: relationships to water temperature and food availability. Journal of Experimental Marine Biology and Ecology 111:159-179.

Paine, R. T., and S. A. Levin. 1981. Intertidal landscapes: disturbance and the dynamics of pattern. Ecological Monographs 51:145-178.

Pascual, M., P. Mazzega, and S. A. Levin. 2001. Oscillatory dynamics and spatial scale: the role of noise and unresolved pattern. Ecology 82:2357-2369.

Pascual, M., M. Roy, F. Guichard, and G. Flierl. 2002a. Cluster size distributions: signatures of self-organization in spatial ecologies. Philosophical Transactions of the Royal Society of London B 357: 657-666.

Pascual, M., M. Roy, and A. Franc. 2002b. Simple temporal models for ecological systems with complex spatial patterns. Ecology Letters 5:412-419.

Ranta, E., and V. Kaitala. 1997. Travelling waves in vole population dynamics. Nature 390:456.

Ranta, E., V. Kaitala, and J. Lindstrom. 1997. Dynamics of Canadian lynx populations in space and time. Ecography 20:454-460.

Renshaw, E., and E. D. Ford. 1983. The interpretation of process from pattern using two-dimensional spectral analysis: methods and problems of interpretation. Applied Statistics 32:51-63.

- 1984. The description of spatial pattern using two-dimensional spectral analysis. Vegetatio 56:75-85.

Rietkerk, M., M. C. Boerlijst, F. van Langevelde, R. HilleRisLambers, J. van de Koppel, L. Kumar, C. A. Klausmeier, et al. 2002. Selforganization of vegetation in arid ecosystems. American Naturalist 160:524-530.

Riisgard, H. U. 2001. On measurement of filtration rates in bivalves. The stony road to reliable data: review and interpretation. Marine Ecology Progress Series 211:275-291.

Rohani, P., T. J. Lewis, D. Grunbaum, and G. D. Ruxton. 1997. Spatial 
self-organization in ecology: pretty patterns or robust reality? Trends in Ecology \& Evolution 12:70-74.

Rovinsky, A. B., and M. Menzinger. 1992. Chemical-instability induced by a differential flow. Physical Review Letters 69:1193-1196.

. 1993. Self-organization induced by the differential flow of activator and inhibitor. Physical Review Letters 70:778-781.

Rovinsky, A. B., H. Adiwidjaja, V. Z. Yakhnin, and M. Menzinger. 1997. Patchiness and enhancement of productivity in plankton ecosystems due to the differential advection of predator and prey. Oikos 78:101-106.

Scholten, H., and A. C. Smaal. 1998. Responses of Mytilus edulis L. to varying food concentrations: testing EMMY, an ecophysiological model. Journal of Experimental Marine Biology and Ecology 219: 217-239.

Seuront, L., and N. Spilmont. 2002. Self-organized criticality in intertidal microphytobenthos patch patterns. Physica A Statistical Mechanics and Its Applications 313:513-539.

Snover, M. L., and J. A. Commito. 1998. The fractal geometry of Mytilus edulis L. spatial distribution in a soft-bottom system. Journal of Experimental Marine Biology and Ecology 223:53-64.

Sole, R. V., D. Alonso, and A. McKane. 2002. Self-organized instability in complex ecosystems. Philosophical Transactions of the Royal Society of London B 357:667-681.

Sukhotin, A. A., D. Abele, and H. O. Portner. 2002. Growth, metabolism and lipid peroxidation in Mytilus edulis: age and size effects. Marine Ecology Progress Series 226:223-234.

Svane, I., and M. Ompi. 1993. Patch dynamics in beds of the blue mussel Mytilus edulis L.: effects of site, patch size, and position within a patch. Ophelia 37:187-202.
Toomey, M. B., D. McCabe, and J. E. Marsden. 2002. Factors affecting the movement of adult zebra mussels (Dreissena polymorpha). Journal of the North American Benthological Society 21:468-475. Turing, A. M. 1952. The chemical basis of morphogenesis. Philosophical Transactions of the Royal Society of London B 237:3772.

Valentin, C., and J. M. d'Herbes. 1999. Niger tiger bush as a natural water harvesting system. Catena 37:231-256.

Valentin, C., J. M. d'Herbes, and J. Poesen. 1999. Soil and water components of banded vegetation patterns. Catena 37:1-24.

van de Koppel, J., and M. Rietkerk. 2004. Spatial interactions and resilience in arid ecosystems. American Naturalist 163:113-121.

van der Wal, D. 2002. Tidal heights and streams along the coastal water of the Netherlands and adjacent areas. Den Helder, Koninklijke Marine, Dienst der Hydrografie, The Hague.

von Hardenberg, J., E. Meron, M. Shachak, and Y. Zarmi. 2001. Diversity of vegetation patterns and desertification. Physical Review Letters 87. Article 198101.

Widdows, J., J. S. Lucas, M. D. Brinsley, P. N. Salkeld, and F. J. Staff. 2002. Investigation of the effects of current velocity on mussel feeding and mussel bed stability using an annular flume. Helgoland Marine Research 56:3-12.

Wildish, D. J., and D. D. Kristmanson. 1984. Importance to mussels of the benthic boundary layer. Canadian Journal of Fisheries and Aquatic Sciences 41:1618-1625.

Wootton, J. T. 2001. Local interactions predict large-scale pattern in empirically derived cellular automata. Nature 413:841-844.

Editor: Jonathan B. Losos Associate Editor: James P. Grover 